\title{
THE ORIGIN AND EARLY EVOLUTION OF CLOSE BINARY STARS
}

\author{
I. W. ROXBURGH \\ (London, U.K.) \\ (Manuscript not received by November 6, 1967.)
}

